\title{
Clinical Evaluation of Porcelain Fused to Electroformed Gold Coping Crowns: Preliminary Results after 30-43 Months
}

\author{
Yuji Kokubo, DDS, PhD, ${ }^{a}$ Mitsuyoshi Tsumita, DDS, ${ }^{a}$ Chikahiro Ohkubo, DDS, PhD, ${ }^{b}$ \\ Satoe Sakurai, DDS, ${ }^{c}$ and Shunji Fukushima, DDS, $\mathrm{PhD}^{\mathrm{a}}$ \\ ${ }^{a}$ Department of Fixed Prosthodontics, School of Dental Medicine, Tsurumi University, Yokohama, Japan \\ ${ }^{\mathrm{b}}$ Department of Removable Prosthodontics, School of Dental Medicine, Tsurumi University, Yokohama, Japan \\ ${ }^{c}$ Division of Oral and Maxillofacial Implantology, School of Dental Medicine, Tsurumi University, Yokohama, \\ Japan
}

\section{Clinical significance}

Auro Galvano Crowns (AGCs) were clinically evaluated and the preliminary results were considered acceptable. The cumulative survival rate was $96.1 \%$ after a maximum of 43 months' function.

\begin{abstract}
Purpose: Porcelain-fused-to-gold copings prepared by the electroforming technique were introduced as an alternative to conventional metal/ceramic crowns. However, there are few clinical studies that have evaluated this technique. The purpose of this study was to prospectively evaluate the clinical performance of Auro Galvano Crowns (AGCs).

Methods: One hundred and twenty-seven AGCs were used to treat patients at the Tsurumi University Dental Hospital from October 2002 to December 2003. All the crowns were evaluated using the modified California Dental Association (CDA) quality assessment system at baseline and at all follow-up appointments.

Results: A total of 122,119 , and 72 crowns were examined at the 1-, 2-, and 3-year follow-ups, respectively. During the observation period, four crowns were removed because of partial fracture of the veneered porcelain in premolar and posterior teeth. No chips were detected during this observation period. All of the crowns examined were rated as satisfactory according to the modified CDA quality assessment system. During this period, the cumulative survival rate was $96.1 \%$.

Conclusion: Within the limitations of this clinical study, AGCs luted with adhesive resin cement functioned satisfactorily with a relatively low fracture rate compared to porcelain-fused-to-metal (PFM) and

\section{Corresponding to: Dr Yuji Kokubo}

Department of Fixed Prosthodontics, School of Dental

Medicine, Tsurumi University

2-1-3 Tsurumi Tsurumi-ku, Yokohama City 230-8501, Japan

Tel: +81-45-581-1001, Fax: +81-45-573-9599

E-mail:kokubo-y@tsurumi-u.ac.jp
\end{abstract}

Received on September 7, 2006 / Accepted on December 18, 2006 all-ceramic crowns. Since the observation period was short, long-term observation will be necessary in order to further evaluate these crowns.

Key words: electroformed metal-ceramic crown, clinical study, electroforming technique, gold coping

\section{Introduction}

Achieving esthetic results is one of the important goals of dental restoration. In the late 1950s, vacuum-fired, porcelain-fused-to-metal (PFM) crowns were introduced onto the market by Vines et al. ${ }^{1}$ Since then, various preparation designs, and impression and laboratory techniques with new materials, have been advocated in order to improve the marginal fit, esthetics, and durability. PFM crowns are currently one of the most predictable and popular types of restoration. ${ }^{2}$ However, in cases involving esthetic restoration, gingival discoloration of the metal copings in contact with the thin soft tissue around the preparation margin has been a significant problem. In order to overcome this problem, PFM crowns with porcelain shoulders were developed; these provided clinically acceptable marginal adaptation. ${ }^{3}$ Electroformed gold copings were introduced to dentistry in 1961 by Rogers and Armstrong. ${ }^{4}$ This technique, which has been improved since the early 1990s, does not require casting, and the gold coping can routinely be made to a uniform thickness using $24 \mathrm{~K}$ gold.

When selecting final restorations, esthetics, marginal adaptation, and durability are very important factors to consider. Electroformed gold copings enable the porcelain crown to look esthetically more natural around the soft tissue. There is no darkening of the soft tissue around the 


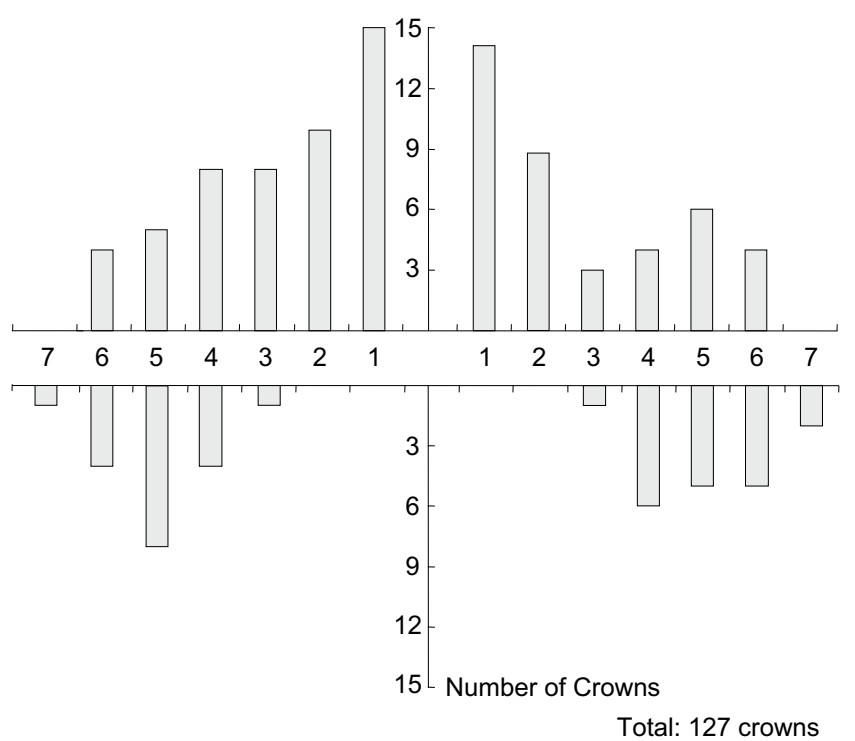

Fig. 1 Baseline distribution of AGCs.

crown margin, as experienced with PFM crowns. Setz et $\mathrm{al}^{5}$ reported that the mean cement film thickness at the Auro Galvano Crown (AGC; Wieland Edelmetalle KG, Pforzheim, Germany) margin was less than $20 \mu \mathrm{m}$ in vitro. In another in vitro study, ${ }^{6}$ the marginal fit of electroformed ceramometal crowns $(36 \mu \mathrm{m})$ was superior to the fit of conventionally cast ceramometal crowns. Petteno et $\mathrm{al}^{7}$ reported that the mean marginal fit of AGCs was $32 \pm 14 \mu \mathrm{m}$ in vitro. In a further in vitro study, Shiratsuchi et $\mathrm{al}^{8}$ revealed that a deep chamfer preparation design of AGC after firing exhibited the best marginal adaptation (23.96-25.72 $\mu \mathrm{m})$ compared to a shoulder preparation design. On the other hand, in the only in vivo study conducted to date, Kokubo et $\mathrm{al}^{9} \mathrm{re}^{-}$ ported that the marginal fit of the AGCs was 40.6 $\mu \mathrm{m}$, which was smaller than that for CAD/CAMgenerated all-ceramic crowns. ${ }^{10,11}$

Krieg $^{12}$ reported a failure rate of $2.4 \%$ for AGCs after an average of 4.1 years' function. Erpenstein et $\mathrm{al}^{13}$ demonstrated in their longterm study that AGC restorations were superior to glass-ceramic restorations and comparable to PFM restorations. However, there are very few reports on the durability of AGCs, particularly for Japanese patients. In general, the size of Japanese people's teeth is smaller than that of European people, which might affect the success rate.

The purpose of this study was to evaluate AGCs in all areas with a prospective study design in Japan. This clinical study was designed to include an up to five-year follow-up. In this report, the preliminary 30-44 month follow-up results are described.

\section{Materials and methods}

A total of 127 AGCs were placed at Tsurumi University Hospital from October 2002 to December 2003. The 54 patients participating in this study consisted of 10 men and 44 women (ranging in age from 21 to 67 years) who were treated with AGCs. Their informed consent was obtained prior to participating in this study. The criteria for patient selection were as follows: each patient was not a heavy bruxer or clencher (based on patient interviews), was less than 70 years old, understood the purpose of this study, agreed to participate in follow-up examinations for up to 5 years, did not have high caries activity (did not have the same natural tooth treated more than two times within one year), and did not have severe periodontal problems (one periodontist examined all patients, and after periodontal conditions were satisfied, the treatment started). Prior to starting, the study was reviewed and approved by the ethics committee of Tsurumi University (No. 108).

Two dentists placed the $127 \mathrm{AGCs}$ in the patients' oral cavities. The distribution of the crowns is shown in Figure 1; maxillary incisors were the most frequently restored, and no mandibular anterior crowns were placed. Two dentists treated all the patients, and all the AGCs in this study were fabricated in the hospital laboratory by experienced dental technicians. A special preparation bur (All-Ceramic Preparation Kit; Shofu, Kyoto, Japan) was used to make a chamfer marginal preparation that included a minimum occlusal reduction of $1.5 \mathrm{~mm}$ and a chamfer width of $0.8 \mathrm{~mm}$. All line angles of the abutment teeth were rounded in order to prevent any stress concentration, and then impressions were made using vinyl polysiloxane impression material (Exafine; GC Corp., Tokyo, Japan). The working casts were fabricated with Type IV stone (New Fuji Rock; GC Corp.), and the trimmed dies were coated with two layers (approximately 24- $\mu \mathrm{m}$ thick) of die spacer (Die Spacer Kit; Benzar-Dental AG, Zurich, Switzerland) to within 1 $\mathrm{mm}$ of the finish line.

All the electroformed gold copings were conventionally made on dies with a uniform thick- 
ness of $0.3 \mathrm{~mm}$ using AGC Micro (Wieland, Pforzheim, Germany) as follows:

1. Each die was duplicated using AGC dubliGum and hardener;

2. AGC super hard plaster was poured in the duplicating mold;

3. The plaster of the duplicate die was dried in the microwave oven;

4. An AGC copper rod was fitted in the duplicate die with a small portion of contact adhesive;

5. AGC conductive silver lacquer was applied evenly up to the preparation margin;

6. AGC shrink-fit plastic tubing was fitted onto the copper rod close to the plaster die;

7. The power level of the AGC Micro was determined;

8. Gold electrolyte was poured into a beaker;

9. The prepared parts were mounted and then the unit started up;

10. The copper rod was cut after electroforming, and the plaster die was dissolved from the crown using AGC plaster remover in an ultrasonic unit;

11. The layer of conducting silver lacquer was boiled out in nitric acid (25\%);

12. After deposition of the gold coping, the stone die was cleaned in an ultrasonic cleaner;

13. The margin of each coping was trimmed back to the correct length with a fine abrasive stone;

14. The electroformed surface was sandblasted with aluminum oxide;

15. An AGC gold bonder was applied to the surface;

16. The AGC gold bonder was predried in a furnace held at $920^{\circ} \mathrm{C}$;

17. Veneering porcelain (Zeoce light; Yamamoto Precious Metal Co., Osaka, Japan) was fired on each electroformed coping according to the manufacturer's instructions; opaque porcelain was fired from $450^{\circ} \mathrm{C}$ to $920^{\circ} \mathrm{C}$ for 5 minutes in a vacuum with a 1-minute hold at peak temperature, dentine porcelain was fired from $550^{\circ} \mathrm{C}$ to $900^{\circ} \mathrm{C}$ for 6 minutes in a vacuum with a 1-minute hold time at peak temperature. Glazing was carried out from $550^{\circ} \mathrm{C}$ to $880^{\circ} \mathrm{C}$ for 4 minutes with a 1 -minute hold at peak temperature using an electric furnace (Austromat 3001; Dekema, Freilassing, Germany).

All the crowns were luted with adhesive resin cements; GC Fuji Luting S (GC Corp., Tokyo,
Japan) was used for 116 crowns, and Panavia F 2.0 (Kuraray Medical Inc., Okayama, Japan) was used for 11 crowns. One hundred and ten teeth were non-vital, and 17 teeth were vital.

The examinations were designed to be performed at the time of cementation (baseline), and every year thereafter for five years. Each examination was performed by two of the authors of this report using the modified California Dental Association (CDA) ${ }^{14}$ quality evaluation system to assess the marginal integrity, surface, color, and anatomic form. The examiners were different from the dentists who fitted each crown. The factors in the modified CDA system were rated as one of the following: satisfactory/excellent or acceptable, or not acceptable/correction or replacement (Table 1). The two investigators examined all the restorations independently of each other. In cases of disagreement between the two investigators, the crowns were reexamined and discussed, and a joint decision was made in order to attain the final score. Before starting, the investigators were calibrated for several typical clinical situations. The condition of the soft tissue surrounding the restored teeth and the control teeth, such as the amount of dental plaque ${ }^{15}$ and gingival bleeding, ${ }^{16}$ was also recorded during the examination. The fracture, chipping, cracking, and the occurrence of marginal caries of each crown were also checked at the same time. All removed crowns were classified as failed (Fig. 2); other problems such as small chipping and cracking were corrected.

The cumulative survival rate was calculated (SPSS Base 10.0; SPSS Inc., Chicago, IL, USA) using the Kaplan-Meier analysis (cumulative method). ${ }^{17}$ The crowns lost to follow-up were censored, and all fractures noticed by patients were recorded at the time of fracture after baseline.

\section{Results}

Table 2 and Figure 3 show the cumulative survival rate of the AGCs during each time period. All crowns, with the exception of those eliminated for various reasons (fracture, removed, and lost to follow-up), were followed for at least a two-year period of function. Forty-six crowns were not included in the 3-year follow-up because 3 years had yet to elapse from the time of crown cementation.

A total of 122 crowns in 51 patients were ex- 
Table 1 Criteria for modified CDA rating.

\begin{tabular}{|c|c|}
\hline \multicolumn{2}{|l|}{ Margin integrity } \\
\hline Excellent: & $\begin{array}{l}\text { No visible evidence of a crevice along margin into which explorer will penetrate. No discolor- } \\
\text { ation on the margin between the restoration and the tooth structure. }\end{array}$ \\
\hline Acceptable: & $\begin{array}{l}\text { Visible evidence of slight marginal discrepancy with no evidence of decay; repair can be made } \\
\text { or is unnecessary. Discoloration on the margin between the restoration and the tooth structure. }\end{array}$ \\
\hline Correction: & $\begin{array}{l}\text { Faulty margins that cannot be properly repaired. Penetrating discoloration along the margin of } \\
\text { the restoration in pulpal direction. Retained excess cement. }\end{array}$ \\
\hline Replacement: & $\begin{array}{l}\text { Mobile restoration. Fractured restoration. Caries continuous with margin of restoration. Tooth } \\
\text { structure fractured. }\end{array}$ \\
\hline \multicolumn{2}{|l|}{ Color } \\
\hline Excellent: & No mismatch in color, shade, and/or translucency between restorations and adjacent teeth. \\
\hline Acceptable: & Slight mismatch between shade of restorations and adjacent teeth. \\
\hline Correction: & $\begin{array}{l}\text { Mismatch between restorations and adjacent tooth or teeth outside normal range of color, } \\
\text { shade, and/or translucency. }\end{array}$ \\
\hline Replacement: & Shade in gross disharmony with adjacent teeth. \\
\hline \multicolumn{2}{|l|}{ Surface } \\
\hline Excellent: & Restoration surface is smooth. No irritation of adjacent tissue is occurring. \\
\hline Acceptable: & Restoration surface is slightly rough or pitted, can be polished. \\
\hline Correction: & Surface grossly irregular not related to anatomy and not subject to correction. \\
\hline Replacement: & Surface is fractured. Porosities in the crown material. \\
\hline \multicolumn{2}{|l|}{ Anatomic form } \\
\hline Excellent: & $\begin{array}{l}\text { Restoration contour in functional harmony with adjacent teeth and soft tissues with good indi- } \\
\text { vidual anatomic form. }\end{array}$ \\
\hline Acceptable: & $\begin{array}{l}\text { Restoration slightly overcontoured. Restoration slightly undercontoured. Occlusion is not com- } \\
\text { pletely functional. Marginal ridges slightly undercontoured. Contact slightly open. Facial flat- } \\
\text { ting is present. Lingual flatting is present. }\end{array}$ \\
\hline Correction: & $\begin{array}{l}\text { Restorations grossly undercontoured. Restorations slightly overcontoured. Occlusion is affect- } \\
\text { ed. Contact is faulty. Marginal overhang is present. }\end{array}$ \\
\hline Replacement: & $\begin{array}{l}\text { Traumatic occlusion. Gross underocclusion. Restoration causes unremitting pain in tooth or ad- } \\
\text { jacent tissue. Damage is occurring to tooth, soft tissue, or supporting bone. }\end{array}$ \\
\hline
\end{tabular}

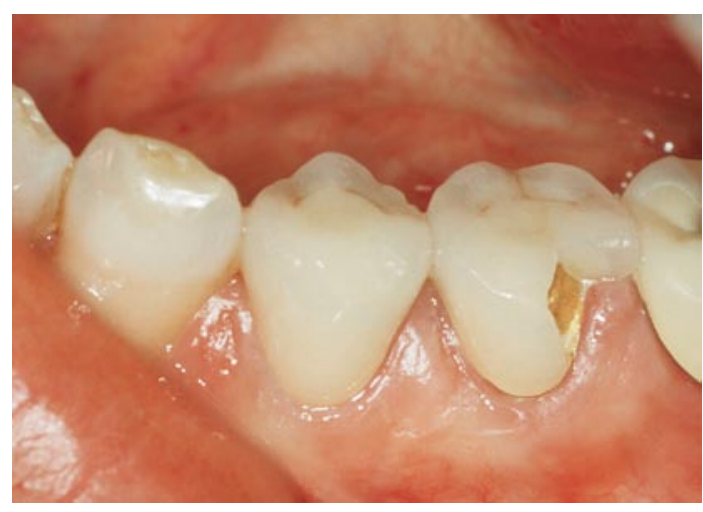

Fig. 2 Porcelain fracture of AGC after 12 months from baseline, requiring a new crown.

Table 2 Cumulative survival rate of AGCs during each period.

\begin{tabular}{lcccc}
\hline & No. of crowns & $\begin{array}{l}\text { No. of crowns } \\
\text { failed }\end{array}$ & $\begin{array}{l}\text { No. of crowns } \\
\text { lost to follow-up }\end{array}$ & $\begin{array}{c}\text { CSR } \\
(\%)\end{array}$ \\
\hline Baseline & 127 & 0 & 0 & \\
1 year & 127 & 3 & 5 & 97.6 \\
2 years & 119 & 0 & 0 & 97.6 \\
3 years & 72 & 1 & 0 & 96.1 \\
\hline
\end{tabular}

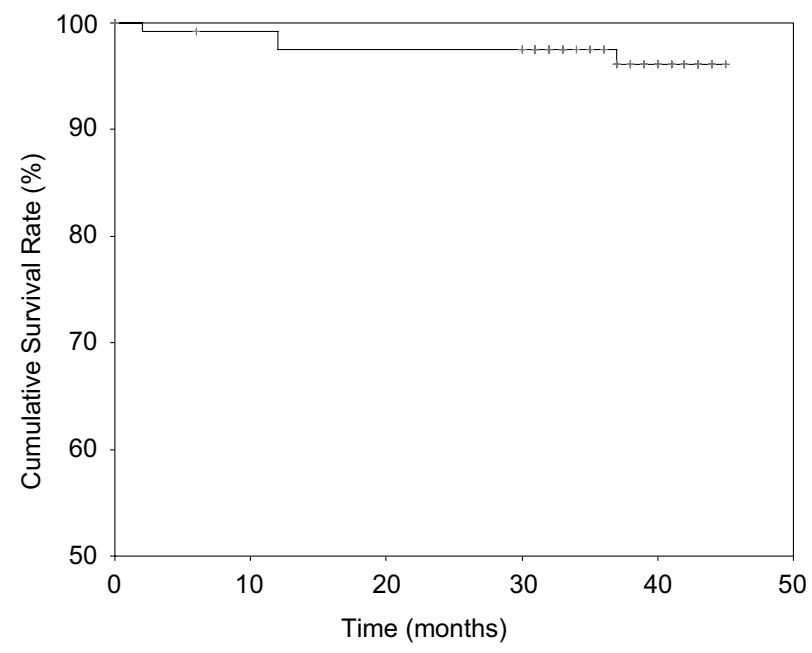

Fig. 3 Kaplan-Meier cumulative survival rate of failed AGCs (Four AGCs failed during this period; 2, 12, 12, and 37 months after baseline). 
Table 3 Quality of AGCs at baseline and 1-, 2-, and 3-year follow-ups according to modified CDA (\%).

\begin{tabular}{|c|c|c|c|c|c|}
\hline & & \multicolumn{2}{|c|}{ Satisfactory } & \multicolumn{2}{|c|}{ Not acceptable } \\
\hline & & Excellent & Acceptable & Correction & Replacement \\
\hline \multirow{4}{*}{ Marginal integrity } & Baseline & 81.1 & 18.9 & 0 & 0 \\
\hline & 0-1 year & 79.2 & 20.2 & 0 & 0 \\
\hline & 1-2 year & 77.3 & 22.7 & 0 & 0 \\
\hline & 2-3 year & 79.7 & 20.3 & 0 & 0 \\
\hline \multirow[t]{4}{*}{ Color } & Baseline & 98.4 & 1.6 & 0 & 0 \\
\hline & 0-1 year & 100 & 0 & 0 & 0 \\
\hline & 1-2 year & 99.2 & 0.8 & 0 & 0 \\
\hline & 2-3 year & 100 & 0 & 0 & 0 \\
\hline \multirow[t]{4}{*}{ Surface } & Baseline & 100 & 0 & 0 & 0 \\
\hline & 0-1 year & 100 & 0 & 0 & 0 \\
\hline & 1-2 year & 100 & 0 & 0 & 0 \\
\hline & 2-3 year & 98.6 & 1.4 & 0 & 0 \\
\hline \multirow[t]{4}{*}{ Anatomic form } & Baseline & 99.2 & 0.8 & 0 & 0 \\
\hline & 0-1 year & 98.3 & 1.7 & 0 & 0 \\
\hline & 1-2 year & 99.2 & 0.8 & 0 & 0 \\
\hline & 2-3 year & 98.6 & 1.4 & 0 & 0 \\
\hline
\end{tabular}

amined after one year. Four patients who col- $^{-}$ lectively had five crowns dropped out for the following reasons: two patients (two crowns) moved away from the region, one patient (two crowns) became sick, and one patient (one crown) was too busy to attend the appointments. However, two patients attended the 6 -month examination. One crown (maxillary first premolar) was remade because of a fracture of the veneered porcelain 2 months after baseline. Two mandibular first and second premolar crowns were removed after 12 months because of partial fractures of the veneered porcelain (Fig. 2). All the fractures were due to cohesive failure. The cumulative survival rate was $97.6 \%$ after 1 year.

During the 1-2 year period, 119 crowns were followed. No patients dropped out, and no crowns failed during this period. The cumulative survival rate of the AGCs after 2 years was $97.6 \%$.

During the 2-3 year period, no patients were lost to follow-up. One maxillary first molar crown fractured after 37 months. During this observation period, the cumulative survival rate was $96.1 \%$.

All of the crowns examined were rated as satisfactory with regard to marginal integrity, color, surface, and anatomic form at all follow-ups. There were no corrections at the follow-ups (Table 3). One porcelain fracture, which necessitated replacement of the crown, was recorded during these follow-ups.

The average plaque index scores of the AGCs and the control teeth at the baseline, $1^{-}, 2^{-}$, and 3 -year evaluations were $0.14,0.09,0.12$, and 0.14 , and $0.23,0.17,0.16$, and 0.15 , respectively.

The average scores for bleeding during probing of the AGCs and the control teeth at the baseline, $1^{-}, 2-$, and 3-year evaluations were $0.03,0.04$, 0.07 , and 0.04 , and $0.09,0.04,0.12$, and 0.07 , respectively.

No secondary caries were clinically detected during these periods.

\section{Discussion}

It is apparent that a $24 \mathrm{~K}$ coping offers esthetic advantages compared with a conventional ceramometal alloy coping after the porcelain is applied. After making the impression and master cast, no investment and casting procedure is required. The electroforming process is completed in the laboratory directly on the duplicated die; any excess gold is removed with a silicon wheel. Hammerl et $\mathrm{al}^{18}$ discovered that $87 \%$ of the AGCs had overhanging margins due to the above mentioned technical reasons. According to the modified CDA criteria, the marginal integrity of most of the crowns was excellent because of the coping fabrication procedure and good clinical marginal 
gap. ${ }^{9}$ Compared with Procera crowns, ${ }^{19}$ there were $10 \%$ more "excellent" ratings; it seemed to be easier for the AGCs to get an excellent rating for marginal integrity.

Kokubo et $\mathrm{al}^{19}$ reported on the clinical evaluation of Procera AllCeram crowns, performed using the same method as that used in our research, and found a lower success rate compared to this study. Furthermore, there was no minor porcelain chipping of the AGCs. Only veneered porcelain fractures, which necessitated crown replacement, were observed (Fig. 3). Vence ${ }^{20}$ and Raigrodski et $\mathrm{al}^{21}$ demonstrated that the disadvantages of AGCs were an uncertain bond quality of the porcelain to the coping and low coping strength. These might be the reasons for the fractures observed in this study.

During this observation period, four premolar crowns and one molar crown failed. The coping was thin; consequently, the porcelain thickness tended to be greater in the premolar and molar areas. Porcelain is a brittle material with low tensile strength and all the partial porcelain fractures observed were from the gold coping. Saitoh $^{22}$ recommended that if the porcelain thickness on the gold coping is built up to more than $2.4 \mathrm{~mm}$, it would be preferable to fix the reinforcing framework around the gold coping in order to avoid porcelain fracture after functioning. Krieg ${ }^{12}$ reported an AGC failure rate of $2.4 \%$, with an average postoperative period of 4.1 years, and presumed high posterior crown failures. This result was different from the result of Erpenstein et al $^{13}$ who demonstrated that the fracture rate of AGC premolars and molars was lower than that of anterior AGCs after 7 years' observation, whereas partial ceramic failure was observed in the AGCs, as shown in our study. Oden et $\mathrm{al}^{23}$ reported that $3 \%$ of the Procera AllCeram crowns experienced fractures during a 5-year clinical trial, and the failure rate for molars was the highest compared with the premolars, canines, and incisors. In other crowns, the survival rates regarding fracture of ceramic CAD/CAM-generated In-Ceram Alumina and In-Ceram Spinell posterior crowns after a mean time of $39 \pm 11$ months were $92 \%$ and $100 \%$, respectively. ${ }^{24}$ Other investigators ${ }^{25-27}$ reported a greater than $98 \%$ success rate for InCeram crowns, which was superior to the results obtained in this report. The cumulative survival rate after 43 months of function was $96.1 \%$, which was lower than for all-ceramic crowns and PFM crowns. ${ }^{28}$
The results of the CDA evaluation rated the color, surface, and anatomic form as satisfactory, with more than $98 \%$ rated as excellent. The "excellent" percentage was very high; it seemed very easy for the AGCs to get an excellent rating. There are no clinical data on the AGCs evaluated using the CDA's quality assessment system; therefore, it is difficult draw comparisons with other reports.

All the crowns in this study were luted using adhesive resin cements, and no crowns had loosened during this period. AGCs generally fit the abutment teeth well; therefore, high viscosity luting cements should be selected to avoid a riseup during the seating of the crown.

The probing index revealed little plaque and bleeding compared to another study of Procera AllCeram crowns. ${ }^{19}$ Before starting this study, a periodontist examined the periodontal condition of the patients; consequently, the average score of all crowns was very low. In this study, the scores for the AGCs tended to be lower compared to the control teeth.

Since the observation period in this study was short, the intention is to continue to follow the patients for a longer period of time.

\section{Conclusion}

AGCs were fabricated for 127 teeth at Tsurumi University Dental Hospital from October 2002 to December 2003 and evaluated using modified CDA criteria. The preliminary 30-43 month follow-up results for these crowns were as follows:

1. Four crowns were removed during this observation period; all the fractures were partial porcelain fracture from the gold copings.

2. Fractures occurred in the premolar and molar regions.

3. The cumulative survival rate was $96.1 \%$.

4. According to the CDA criteria, $100 \%$ of the functioning crowns were rated as satisfactory.

Within the limitation of this clinical study, AGCs luted with adhesive resin cement functioned satisfactorily, with a relatively low fracture rate compared to PFMs and all-ceramic crowns.

Acknowledgements: The authors gratefully acknowledge the editorial assistance of Mrs. Jeanne Santa Cruz, Dallas, TX, USA. 


\section{References}

1. Vines RF, Semmelman JO, Lee PW et al. Mechanisms involved in securing dense, vitrified ceramics from pre-shaped partly crystalline bodies. J Am Ceram Soc 41: 304-308, 1958.

2. Palmqvist S, Swartz B. Artificial crowns and fixed partial dentures 18 to 23 years after placement. Int J Prosthodont 6: 279-285, 1993.

3. Belles DM, Cronin RJ Jr, Duke ES. Effect of metal design and technique on the marginal characteristics of the collarless metal ceramic restoration. J Prosthet Dent 65: 611-619, 1991.

4. Rogers OW, Armstrong BW. Electroforming a gold matrix for indirect inlays. J Prosthet Dent 11: 959-966, 1961.

5. Setz J, Diehl J, Weber H. The marginal fit of cemented galvanoceramic crowns. Int $J$ Prosthodont 2: 61-64, 1989.

6. Holmes JR, Pilchen ES, Rivens JA et al. Marginal fit of electroformed ceramometal crowns. J Prosthod 5: 111-114, 1996.

7. Petteno D, Schierano G, Bassi F et al. Comparison of marginal fit of 3 different metal-ceramic systems: An in vitro study. Int J Prosthodont 13: 405-408, 2000.

8. Shiratsuchi H, Komine F, Kakehashi Y et al. Influence of finish line design on marginal adaptation of electroformed metal-ceramic crowns. J Prosthet Dent 95: 237-242, 2006.

9. Kokubo Y, Tsumita M, Ohkubo C et al. Clinical marginal gap of porcelain fused to electroformed gold coping crowns. Euro J Prosthodont Rest Dent 14: 85-89, 2006.

10. Kokubo Y, Ohkubo C, Tsumita M et al. Clinical marginal and internal gaps of Procera AllCeram crowns. J Oral Rahabil 31: 1-5, 2004.

11. Kokubo Y, Nagayama Y, Tsumita M et al. Clinical marginal and internal gaps of In-Ceram crowns fabricated using the GN-I system. J Oral Rahabil 32: 753-758, 2005.

12. Krieg G. First long-term results of galvanoceramic crowns modum AGC: a 9-year study. Quintessence 46: 783-788, 1994.

13. Erpenstein H, Borchard R, Kerschbaum T. Longterm clinical results of galvano-ceramic and glassceramic individual crowns. J Prosthet Dent 83: 530-534, 2000.
14. California Dental Association. Quality Evaluation for Dental Care. - Guidelines for Assessment of Clinical Quality and Professional Performance.Los Angeles: California Dental Association, 1977.

15. Silness J, Löee H. Periodontal disease in pregnancy. II. - Correlation between oral hygiene and periodontal condition.- Acta Odontol Scand 22: 121-135, 1964.

16. Saxer UP, Mühlemann HR. Motivation and education. Schweiz Monatsschr Zahnneilkd 85: 905-919, 1975.

17. Kaplan EL, Meier P. Nonparametric estimation from incomplete observations. J Am Stat Assoc 53: 457-460, 1954.

18. Hammerle CHF, Mesaric W, Lang NP. Marginal fit of porcelain crowns with galvanized frames. Schweiz Monatsschr Zahnmed 104: 740-745, 1994.

19. Kokubo Y, Tsumita M, Nagayama Y et al. Prospective clinical study of Procera AllCeram crowns: 2-3 year preliminary results. Prosthodont Res Pract 5: 80-85, 2006.

20. Vence BS. Electroforming technology for galvanoceramic restorations. J Prosthet Dent 77: 444-449, 1997.

21. Raigrodski AJ, Malcamp C, Rogers WA. Electroforming technique. J Dent Tech 15: 13-16, 1998.

22. Saitoh I. "Total grade up" potential of AGC galvano system. Quintessence Dental Technology 27: 457-467, 2002.

23. Oden A, Andersson M, Krystek-Ondracek I et al. Five-year clinical evaluation of Procera AllCeram crowns. J Prosthet Dent 80: 450-456, 1998.

24. Haselton DR, Diaz-Arnold AM, Hillis SL. Clinical assessment of high-strength all-ceramic crowns. J Prosthet Dent 83: 396-401, 2000.

25. Scotti R, Catapano SD, Elia A. A clinical evaluation of In-Ceram crowns. Int J Prosthodont 8: 320-323, 1995.

26. Pröbster L. Four-year clinical study of glass-infiltrated, sintered alumina crowns. J Oral Rehabil 23: 147-159, 1996.

27. Segal BS. Retrospective assessment of 546 allceramic anterior and posterior crowns in a general practice. J Prosthet Dent 85: 544-550, 2001.

28. Erpenstein H, Kerschbaum T, Fischbach H. Failure rates and clinical findings in crowns and bridges. Dtsch Zahnärztl 47: 315-319, 1992. 